\title{
Ubiquitin fusion degradation 1-like gene dysregulation in bicuspid aortic valve
}

\author{
Salah Ali Mohamed, PhD, ${ }^{a}$ Thorsten Hanke, MD, ${ }^{a}$ Claudia Schlueter, $\mathrm{PhD},{ }^{\mathrm{b}}$ Joern Bullerdiek, $\mathrm{PhD},{ }^{\mathrm{b}}$ \\ and Hans-Hinrich Sievers, MDa
}

From the Department of Cardiac Surgery, University of Schleswig-Holstein Campus Luebeck, Luebeck, Germany, ${ }^{\mathrm{a}}$ and the Center for Human Genetics, University of Bremen, Bremen, Germany. ${ }^{\mathrm{b}}$

Received for publication April 19, 2005; revisions received June 17, 2005; accepted for publication Aug 8, 2005.

Address for reprints: Hans-H. Sievers, MD, Department of Cardiac Surgery, University of Schleswig-Holstein Campus Luebeck, Ratzeburger Allee 160, 23538 Luebeck, Germany (E-mail: sievers@medinf.mu-luebeck.de).

J Thorac Cardiovasc Surg 2005;130:1531-6 $0022-5223 / \$ 30.00$

Copyright (C) 2005 by The American Association for Thoracic Surgery

doi:10.1016/j.jtcvs.2005.08.017
Objective: Bicuspid aortic valve, the most common congenital cardiac malformation, is caused by fusion of valve cushions at the onset of valvulogenesis. Although its exact pathogenesis is still unclear, a genetic basis is appearing more and more likely. Search for a potential candidate gene by reviewing semilunar valve morphogenesis led us to the ubiquitin fusion degradation 1-like gene (UFD1L), which is highly expressed in the cardiac outflow tract during embryogenesis.

Methods: Aortic valves were collected during surgery from 39 patients with bicuspid aortic valve (mean age $56.8 \pm 18.1$ years) and from 38 patients with tricuspid aortic valve (mean age $61.7 \pm 16.1$ years). Fluorescence in situ hybridization was performed for detection of microdeletion, quantitative reverse transcriptasepolymerase chain reaction to measure gene expression, and Western blotting to analyze the amount of UFDIL gene product.

Results: No microdeletion was found in either group in the critical region of chromosome 22 containing the UFDIL gene. UFD1L gene expression, however, was significantly reduced in bicuspid aortic valve samples (median 787-fold) relative to tricuspid aortic valve samples (median 10,887-fold, $P=.001$ ). The amount of UFDIL gene product was also significantly diminished in bicuspid aortic valve samples $(3.9 \pm 2.6$ vs $8.4 \pm 4.8$ optical density units, $P<.05)$.

Conclusion: Bicuspid aortic valve was associated with downregulation of UFDIL gene expression, supporting the hypothesis that bicuspid aortic valve is a genetic disorder, with the UFDIL gene as a potential candidate gene.

B icuspid aortic valve (BAV) is the most common congenital cardiac malformation, with an estimated incidence of $1 \%$ to $2 \%$ in the general population. ${ }^{1}$ BAV not only contributes significantly to the cardiovascular health burden but also poses a challenge to valve surgeons. Knowledge of the pathogenetic mechanisms underlying BAV could help in stratification of treatment modalities. Several family studies have found that anomalies of the left ventricular outflow tract, including BAV, are inherited disorders ${ }^{2}$; their genetic basis, however, remains obscure. Some recent reports suggest that BAV reflects a developmental defect during embryogenesis. ${ }^{3-5}$ At the beginning of valvulogenesis, a population of cells called neural crest cells migrate away from the neural fold and spread throughout the embryo. These cells seem to play a crucial role in normal development of the cardiac outflow tract and semilunar valves. ${ }^{6-8}$ The basic helix-loop-helix transcription factor dHAND* is essential for survival of cells in neural crest-derived ventricular structures and aortic arch arteries. ${ }^{9-11}$ One of the dHAND-dependent genes is the ubiquitin fusion degradation 1-like gene (UFD1L), which is expressed at high levels during embryogenesis, maps to human chromosome 22, an area called

$*$ dHAND $=$ deciduum, heart, autonomic nervous system, neural crest-derived 


\author{
Abbreviations and Acronyms \\ AP-2 = activating enhancer-binding protein 2 \\ BAV = bicuspid aortic valve \\ $\mathrm{CATCH}=$ cardiac defect, abnormal facies, thymic \\ hypoplasia or aplasia and T-cell \\ deficiency, cleft palate, \\ hypoparathyroidism, and hypocalcemia \\ dHAND $=$ deciduum, heart, autonomic nervous \\ system, neural crest-derived \\ $G A P D H=$ reduced glyceraldehyde-phosphate \\ dehydrogenase gene \\ NF-ATc $=$ nuclear factor of activated T cells \\ SRY = sex determining region Y-box 4 (SOX4) \\ TAV $=$ tricuspid aortic valve \\ $T B X 1=\mathrm{T}$-box 1 gene \\ $U F D 1 L=$ ubiquitin fusion degradation 1-like gene
}

the $C A T C H$ region,* and encodes a protein involved in degradation of ubiquinated proteins. These findings suggest that UFDIL gene insufficiency is involved in the development of congenital heart defects, especially malformations in the conotruncal region. We hypothesized that the UFDIL gene might also be dysregulated in BAV, which has not been investigated before.

\section{Materials and Methods}

\section{Study Protocol}

Specimens from 39 patients with BAV (27 male and 12 female, aged $56.9 \pm 18.1$ years) and 38 patients with tricuspid atrial valve (TAV, 25 male and 13 females, aged $61.7 \pm 16.1$ years) were analyzed (Table 1). Valve cusps were collected during surgery and immediately frozen in liquid nitrogen. Only fused leaflets were used for analysis of gene expression and protein analysis.

None of the patients showed clinical signs characteristic of 22q11.2 syndrome. Fluorescence in situ hybridization analysis was performed for detection of microdeletion, reverse transcriptasepolymerase chain reaction for gene expression, and Western blotting for protein analysis.

The study protocol was approved by the institutional ethics committee. Written, informed consent was obtained from each patient.

\section{Microdeletion Analysis}

For fluorescence in situ hybridization analysis, 3-mL samples of venous blood collected from 10 of the patients with BAV were compared with 3-mL samples of venous blood from 10 patients with TAV. Fluorescence in situ hybridization for the DiGeorge syndrome critical region on chromosome 22q11.2 was performed with a dual color probe (N25 LSI/ARSA; Vysis Inc, Downers Grove, Ill). Slides were prepared according to standard cytogenetic procedures. The dual color probe allows simultaneous identification of both number 22 chromosomes. For each patient, at least 10

*CATCH $=$ cardiac defect, abnormal facies, thymic hypoplasia or aplasia and T-cell deficiency, cleft palate, hypoparathyroidism, and hypocalcemia.
TABLE 1. Patient hemodynamic characteristics, underlying systemic diseases, and valve morphologic types

\begin{tabular}{lrr}
\hline & BAV & TAV \\
\hline Aortic valve disease & & \\
$\quad$ Predominant aortic insufficiency & 16 & 9 \\
Predominant aortic stenosis & 6 & 15 \\
$\quad$ Balanced & 17 & 14 \\
Systemic disease & 17 & 17 \\
$\quad$ Hypertension & 3 & 1 \\
Endocarditis & & \\
Chronic obstructive pulmonary & 1 & 3 \\
$\quad$ disease & 3 & 7 \\
$\quad$ Diabetes & 15 & 9 \\
Aneurysm of ascending aorta & 0 & 1 \\
$\quad$ Dissection & & \\
Morphologic types of BAV & & \\
Raphe between left-right coronary & 38 & - \\
$\quad$ sinus & & \\
Raphe between right noncoronary & 1 & - \\
$\quad$ sinus &
\end{tabular}

Entries represent numbers of patients. BAV, Bicuspid aortic valve; TAV, tricuspid aortic valve.

metaphases were scored for possible deletions in the DiGeorge region. Aberrations of less than $10 \%$ in the normal signal pattern were regarded as artifacts.

\section{UFD1L Gene Expression Analysis}

For UFD $1 L$ gene expression studies, tissues from 27 patients with BAV were compared with tissues from 20 patients with TAV. Total RNA was prepared from 200-mg snap-frozen tissue with TRIzol (Invitrogen, Karlsruhe, Germany). Reverse transcription was carried out with $1 \mu \mathrm{g}$ total RNA with the GeneAmp PCR system 2700 (Applied Biosystems, Darmstadt, Germany) in a reaction volume of $25 \mu \mathrm{l}$ containing $7.5 \mu \mathrm{mol} / \mathrm{L}$ random hexamers, $1 \times$ reverse transcription buffer, $220 \mu \mathrm{mol} / \mathrm{L}$ of each deoxynucleotide triphosphate, $20 \mathrm{U}$ ribonuclease inhibitor, and $50 \mathrm{U}$ reverse transcriptase. A $2-\mu \mathrm{L}$ portion of complementary DNA was used for final application to quantify UFDIL messenger RNA. TaqMan reverse transcriptase-polymerase chain reaction was performed with fluorogenic probe and Universal Master mix on ABI PRISM 7000 SDS (Applied Biosystems) according to manufacturer instructions. Polymerase chain reaction products were measured at the threshold cycle at which fluorescence became detectable above the baseline. Levels of UFDIL messenger RNA were normalized to those of the reduced glyceraldehyde-phosphate dehydrogenase gene (GAPDH) and relative to a calibrator. The relative changes in the gene expression are given by $2^{-\Delta \Delta \mathrm{CT}}$, where $\Delta \Delta \mathrm{CT}=(\Delta \mathrm{CTS}$ ample $)-(\Delta \mathrm{CTC}$ alibrator $)$. Amplification primers and detection probes were designed for the UFDIL gene in our laboratory with PrimerExpress software version 2.0 (Applied Biosystems) to cross intron/exon boundaries. Oligosequences are based on those retrieved from the GenBank database (U64444 for hUFDIL and BC029618 for hGAPDH). Forward primer 5'-TCC ACA CAG TAC CGC TGC TTC T-3', reverse primer 5'-TCA GAT GTG GAG AAA GGA GGG AA-3', and 


\begin{tabular}{|c|c|c|c|}
\hline Chromosome 22 & Symbol & Cytogenetic & Full name \\
\hline \multirow{4}{*}{13} & $\begin{array}{l}\text { DGCR } \\
\text { VCF }\end{array}$ & $22 \mathrm{q} 11$ & DiGeorge syndrome critical region \\
\hline & CECR & $\begin{array}{l}22 \mathrm{q} 11 \\
22 \mathrm{q} 11\end{array}$ & $\begin{array}{l}\text { Velocardiofacial syndrome } \\
\text { Cat eye syndrome chromosome region }\end{array}$ \\
\hline & CTHM & $22 \mathrm{q} 11$ & Conotruncal heart malformation \\
\hline & HIRA & $22 \mathrm{q} 11$ & Histone cell cycle regulation, (hA) \\
\hline \multirow{5}{*}{11.2} & TUPLE1 & $22 \mathrm{q} 11$ & Tup-like enhancer of split 1 \\
\hline & CLDN5 & $22 \mathrm{q} 11$ & Claudin 5 \\
\hline & COMT & $22 \mathrm{q} 11.2$ & Catechol-O-methyltransferase \\
\hline & CLTCL1 & $22 \mathrm{q} 11.2$ & Clathrin, heavy polypeptide-like 1 \\
\hline & UFD1L & $22 q 11.2$ & Ubiquitin fusion degradation 1-like \\
\hline 11.2 & CDC45L & $22 \mathrm{q} 11.2$ & CDC45 cell division cycle 45 -like \\
\hline 12 & $T B X 1$ & $22 q 11.2$ & T-box 1 \\
\hline \multirow{8}{*}{13} & ZNF74 & $22 \mathrm{q} 11.2$ & Zinc finger protein- 74 \\
\hline & APOL & $22 \mathrm{q} 12.3$ & Apolipoprotein \\
\hline & Ep300 & $22 \mathrm{q} 13$ & E1A binding protein $\mathrm{p} 300$ \\
\hline & $\mathrm{SCO} 2$ & $22 \mathrm{q} 13$ & $\mathrm{SCO}(\mathrm{h} 2)$ \\
\hline & SOX10 & $22 \mathrm{q} 13$ & SRY-box 10 \\
\hline & MKL1 & $22 \mathrm{q} 13$ & Megakaryoblastic leukemia (t1) \\
\hline & ADSL & $22 \mathrm{q} 13.1$ & Adenylosuccinate lyase \\
\hline & SHANK3 & $22 \mathrm{q} 13.3$ & Sh3 and multiple ankyrin repeat (d3) \\
\hline
\end{tabular}

Figure 1. a, CATCH region on chromosome 22 and its important genes, including UFD1L. b, Fluorescence in situ hybridization study of blood with 22q13.3 (LSI/ARSA) and DiGeorge/VCFS probe. All signals were present in metaphase and interphase cells of patient with BAV and showed no microdeletion in CATCH region. Arrows indicate that the loci are present on both chromosomes in metaphase and interphase cells. C, Positive control with $22 q 11.2$ microdeletion. Arrow indicates one chromosome 22 with only one signal of LSI ARSA control probe in metaphase cell. The second signal is missed, indicating deletion of the 22q11.2 (obtained from Center for Human Genetics, University of Bremen, Germany).
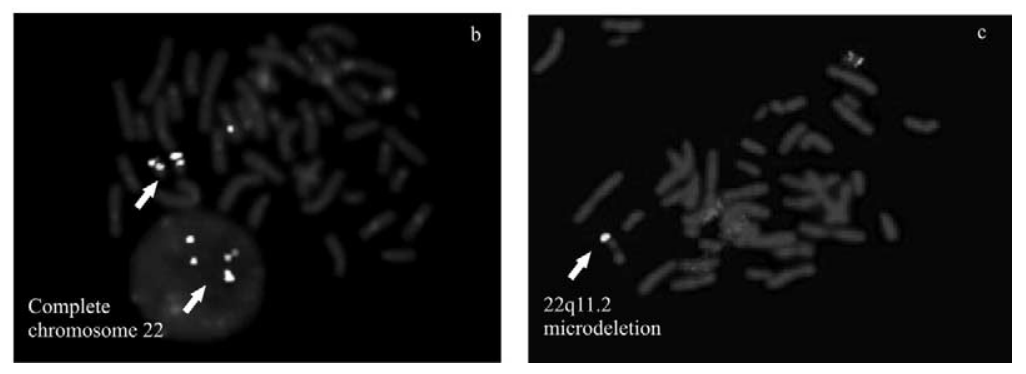

TaqMan FAM-MGB probe 5'-TAG CAT GGC CTA ATG ACA-3' were used to amplify and detect a 77-base pair UFD1L fragment. The human GAPDH predeveloped TaqMan assay reagent VIC-MGB probe (part number 4326317E; Applied Biosystems) was used as endogenous control.

\section{UFD1L Gene Product Analysis}

Protein analysis was performed on 12 patients in each group. For the Western blot, $500 \mathrm{mg}$ valve tissue was homogenized in $300 \mu \mathrm{l}$ lysis buffer (Cell Signaling Technology, Inc, Beverly, Mass). sodium dodecylsulfate-polyacrylamide gel electrophoresis was performed according to the method of Laemmli ${ }^{11 a}$ on an $18 \%$ polyacrylamide gel with $50 \mu \mathrm{g}$ tissue-extracted protein loaded per lane. After electrophoresis, separated proteins were blotted onto an Immobilon membrane (Millipore [UK] Limited, Watford, United Kingdom). Nonspecific sites were blocked by a solution containing $5 \%$ fat-free milk powder in phosphate-buffered saline solution. Membranes were incubated with antibody solution containing 1 $\mu \mathrm{g} / \mathrm{mL}$ anti-human ubiquitin overnight at $37^{\circ} \mathrm{C}$ (R\&D Systems, Minneapolis, Minn). After five washes with blocking buffer, membranes were incubated with the secondary antibody solution containing a 1:2000 dilution of horseradish peroxidase-conjugated goat antimouse antibodies. For detection of protein signals, peroxidase reaction was carried out by enzyme-linked chemilumines- cence (Amersham Biosciences Europe GmbH, Freiburg, Germany). The polypeptide bands were semiquantified by computerized blot scanning and measurement of optical density. A positive control of UFD1L gene product protein was used (Sigma, Taufkirchen, Germany). In addition we applied the $\beta$-actin antibody (Abcam Ltd, Cambridge, United Kingdom) as a loading control antibody.

\section{Statistical Analysis}

Statistical analysis was performed with the Statistical Package for Social Sciences version 9.0 (SPSS GmbH Software, Munich, Germany). Differences among groups were assessed with the MannWhitney $U$ test. The changes in gene expression in the two groups were compared with analysis of variance. Bonferroni adjustment was applied for multiple tests.

\section{Results}

Microdeletion on Chromosome 22

In all investigated cases, no microdeletion of the critical CATCH region on chromosome 22, including the UFD1L gene, was detected (Figure 1, $a$ ). Figure 1, b, shows representative metaphase and interphase cells from a patient with BAV. Figure 1, $c$, shows a positive control sample of the 


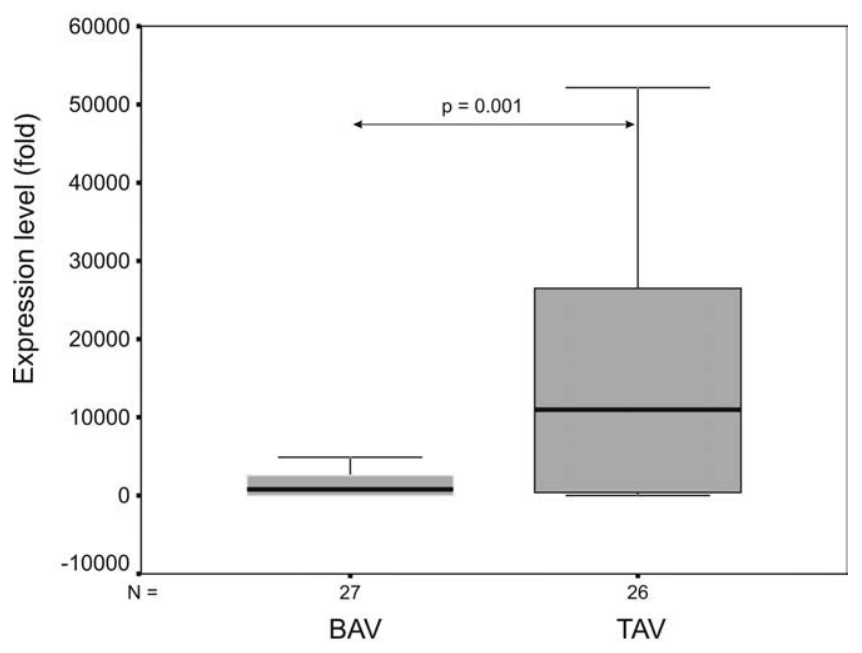

Figure 2. Relative UFD1L gene expressions (box plots) in aortic leaflets from patients with BAV (median 787-fold) and in leaflets from patients with TAV (median 10,887-fold). Numbers were calculated with $2^{-\Delta \Delta C T}$ method. Significantly higher level of UFD1L gene expression was seen in TAV than in BAV $(P=.001)$.

$\mathrm{CATCH}$ region deletion (obtained from the Center for $\mathrm{Hu}-$ man Genetics, University of Bremen, Germany).

\section{UFD1L Gene Expression}

UFDIL gene expression was significantly decreased in BAV. The median expression levels in BAV and TAV, respectively, were 787-fold (maximum 16,845-fold, minimum 7-fold) and 10,887-fold (maximum 52,136-fold, minimum 24-fold, $P=.001$; Figure 2).

\section{UFD1L Gene Product Quantification}

The UFDIL gene product protein level was significantly reduced in BAV (3.9 \pm 2.6 optical density units) relative to TAV (8.4 \pm 4.8 optical density units, $P<.05$; Figure 3 ).

\section{Discussion}

This study shows that BAV is associated with a reduced UFDIL gene expression. It supports the hypothesis of BAV as a genetic disorder and also indicates UFDIL as among the candidate genes warranting further investigation.

$\mathrm{BAV}$ is the most common congenital cardiac malformation, affecting $1 \%$ to $2 \%$ of the general population. ${ }^{1} \mathrm{BAV}$ contributes significantly to the cardiovascular health burden. Comprehensive knowledge of the pathogenesis of BAV may be important for treatment strategies.

A number of mechanisms may be involved, either alone or combined, in the pathogenesis of BAV. Theoretically, epigenetic factors during cardiac morphogenesis, such as fluid forces, may contribute to BAV development in a manner similar to that of factors resulting in impaired valve

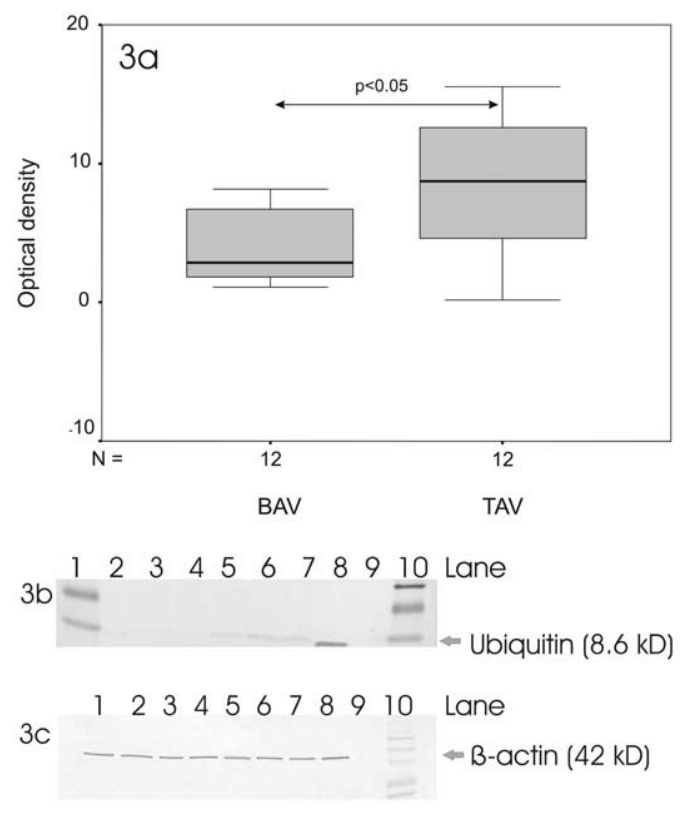

Figure 3. a, UFD1L gene product levels (box plots) in aortic leaflets from patients with BAV and patients with TAV. b, Levels of UFD1L gene product protein on Western blot (arrow) in aortic leaflets from 3 patients with BAV (lanes 2-4) and from 3 patients with TAV (lanes 5-7), in 1 positive pure control (lane 8), in water (lane 9), and in two protein markers (lanes 1 and 10). c, Measurement of amount of protein analyzed by Western blotting, with $\boldsymbol{\beta}$-actin as loading control antibody. Lanes 1 and 8 are positive control, lane 9 is water, and lane 10 is protein marker.

function, valve stiffness, and opening abnormalities. ${ }^{12} \mathrm{Sev}-$ eral recent studies have demonstrated that BAV is inheritable as part of the whole spectrum of anomalies of the left ventricular outflow tract. Wessels and colleagues ${ }^{2}$ even suggest that all left ventricular outflow tract anomalies, including BAV, may be caused by a single gene defect.

A number of studies have shown that 22q11.2 deletions cause a variety of cardiac outflow tract defects. ${ }^{13-15}$ These cardiac defects are also seen after neural crest ablation, suggesting that certain genes controlling neural crest cells may be involved in the development of cardiac outflow tract malformations and may map to chromosome 22. The critical CATCH region of this chromosome consists of many genes, including the UFDIL and T-box 1 (TBXI) genes. Yamagishi and associates ${ }^{10}$ detected the UFDIL gene in all 182 patients with 22q11.2 syndrome in their investigation.

During embryogenesis, the UFDIL gene is highly expressed in certain tissues. It encodes a component of a multienzyme complex involved in the degradation of ubiquitin fusion proteins. A downregulation of the UFDIL gene, hypothetically resulting from an anomalous behavior of neural crest cells, may lead to reduced degradation activities 
and thus explain in part the hypotheses of Sans-Coma and associates, ${ }^{16}$ who demonstrated in Syrian hamsters the fusion of valve cushions as a key factor in the development of congenital BAV. Furthermore, mouse homolog Ufdl gene expression was detected in the cardiac outflow tract at the same time as neural crest cell condensation, before these cells transformed into ectomesenchymal cells.

These observations highlight the important role of the UFDIL gene in the development of ectoderm-derived structures, including neural crest cells. ${ }^{10,17}$ These cells have also been found in developing aortic leaflets, ${ }^{18}$ pointing to the UFDIL gene as a candidate for the pathogenesis of BAV. In our study, no deletion of the critical CATCH region on chromosome 22, including the UFDIL gene, was found in any of the patients with BAV. This was not entirely unexpected, because a microdeletion would theoretically lead to more phenotypic abnormalities. We did find, however, downregulation of the UFDIL gene and consequently diminished amounts of its gene product. Our results accord with the finding that a functional attenuation of chick UFDIL in cardiac neural crest cells results in an increased incidence of conotruncal septation defects. ${ }^{14}$ The exact mode of downregulation of the UFDIL gene and how it induces BAV in human beings remain unclear. Some findings implicate the transcription factor $\mathrm{AP}-2,{ }^{*}$ which is active as a regulator of gene expression during the differentiation and development of neural crest cells. ${ }^{19,20}$ It is also involved in the regulation of transforming growth factor $\alpha,{ }^{21}$ estrogen receptor, ${ }^{22}$ type IV collagenase, ${ }^{23}$ insulinlike growth factor binding $5,{ }^{24}$ and many other genes. A systematic investigation is needed to elucidate the important biologic functions of AP-2 in the regulation of the UFDIL gene.

Another gene that maps to the $\mathrm{CATCH}$ region involved in 22q11.2 syndrome and may be involved in the pathogenesis of BAV is the $T B X 1$ gene. We measured $T B X 1$ gene expressions in 10 patients in each group (data not shown), but we did not find a significant difference between those with BAV and those with TAV. Whether this is because $T B X 1$, unlike $U F D I L$, is not expressed in neural crest cells ${ }^{25}$ remains to be studied.

Ranger and colleagues ${ }^{26}$ and de la Pompa and cowork$\mathrm{ers}^{27}$ have reported that the targeted dysregulation of the transcription factor NF-ATc †resulted in selective absence of the aortic valves, leading to death in utero. A similar phenotype was observed in SRY (sex determining region Y)-box 4 (SOX4)-deficient mice. ${ }^{28}$ Disorders of the latter transcription factors, however, do not lead to the characteristic phenotype of fused leaflets seen in BAV.

A limitation of this study is the fact that it demonstrates only an association, not a causal relationship, between BAV

*AP-2 = activating enhancer-binding protein 2 .

$\dagger \mathrm{NF}-\mathrm{ATc}=$ activating enhancer-binding protein 2 and UFDIL downregulation. Whether the relationship is causal must be determined by in vivo experiments targeting downregulation of the UFDIL gene in an animal model. Also, we did not show pedigree analysis of familial clustering explaining a genetic cause of BAV. Furthermore, only a few neural crest cells could be identified in late fetal aortic semilunar valves as a result of a reduction in their numbers caused by death or failure to divide. ${ }^{29}$ This may have influenced our results, although the ages of our two groups were comparable, and we found no correlation between the age of patients with BAV and the degree of UFDIL gene expression. In addition, the two groups differed with regard to the underlying valvular etiology, with more aortic insufficiencies in the BAV group. Whether this influenced the gene expression remains unclear, but it seems rather unlikely because leaflet fusion was the basic pathology underlying both stenotic and insufficient valves. Although the genetic pathomechanism of BAV is probably far more complicated (regarding, for example, accompanying defects such as coarctation), our findings appear to take the first steps toward an understanding of the genetic basis of BAV.

We thank Sven Hauke and Norbert Drieschner for their valuable help with the fluorescence in situ hybridization analyses.

\section{References}

1. Roberts WC. The congenitally bicuspid aortic valve. Am J Cardiol. 1970;26:72-82.

2. Wessels MW, Berger RM, Frohn-Mulder IM, Roos-Hesselink JW, Hoogeboom JJ, Mancini GS, et al. Autosomal dominant inheritance of left ventricular outflow tract obstruction. Am J Med Genet A. 2005; 134:171-9.

3. McKusick VA. Association of congenital bicuspid aortic valve and Erdheim's cystic medial necrosis. Lancet. 1972;1:1026-7.

4. Nataatmadja M, West M, West J, Summers K, Walker P, Nagata M, et al. Abnormal extracellular matrix protein transport associated with increased apoptosis of vascular smooth muscle cells in Marfan syndrome and bicuspid aortic valve thoracic aortic aneurysm Circulation. 2003;108 Suppl 1:II329-34.

5. Bonderman D, Gharehbaghi-Schnell E, Wollenek G, Maurer G, Baumgartner H, Lang IM. Mechanisms underlying aortic dilatation in congenital aortic valve malformation. Circulation. 1999;99:2138-43.

6. Zigmond MJ, Bloom FE, Landis SC, Roberts JL, Squire LR. Neurogenesis and migration. In: Zigmond MJ, Bloom FE, Landis SC, Roberts JL, Squire LR, editors. Fundamental neuroscience. San Diego: Academic Press; 1998. p. 451-80.

7. Le Douarin NM, Teillet MA. Experimental analysis of the migration and differentiation of neurectodernam mesenchymal derivatives, using a biological cell making technique. Dev Biol. 1974;41:162-84.

8. Kirby ML, Waldo KL. Role of neural crest in congenital heart disease. Circulation. 1990;82:332-40.

9. Srivastava D, Cserjesi P, Olson EN. A subclass of bHLH proteins required for cardiac morphogenesis. Science. 1995;270:1995-9.

10. Thomas T, Yamagishi H, Overbeek PA, Olson EN, Srivastava D. The bHLH factors, dHAND and eHAND, specify pulmonary and systemic cardiac ventricles independent of left-right sidedness. Dev Biol. 1998; 196:228-36.

11. Yamagishi H, Garg V, Matsuoka R, Thomas T, Srivastava D. A molecular pathway revealing a genetic basis for human cardiac and craniofacial defects. Science. 1999;283:1158-61.

11a.Laemmli UK. Cleavage of structural proteins during the assembly of the head of bacteriophage T4. Nature. 1970;227:680-5. 
12. Hove JR, Koster RW, Forouhar AS, Acevedo-Bolton G, Fraser SE, Gharib M. Intracardiac fluid forces are an essential epigenetic factor for embryonic cardiogenesis. Nature. 2003;421:172-7.

13. Momma K, Kondo C, Ando M, Matsuoka R, Takao A. Tetralogy of Fallot associated with chromosome 22q11 deletion. Am J Cardiol. 1995;76:618-21.

14. Ryan AK, Goodship JA, Wilson DI, Philip N, Levy A, Seidel H, et al. Spectrum of clinical features associated with interstitial chromosome 22q11 deletions: a European collaborative study. J Med Genet. 1997; 34:798-804.

15. Yamagishi C, Hierck BP, Gittenberger-De Groot AC, Yamagishi H, Srivastava D. Functional attenuation of UFD1L, a 22q11.2 deletion syndrome candidate gene, leads to cardiac outflow septation defects in chicken embryos. Pediatr Res. 2003;53:546-53.

16. Sans-Coma V, Fernandez B, Duran AC, Thiene G, Arque JM, MunozChapuli R, et al. Fusion of valve cushions as a key factor in the formation of congenital bicuspid aortic valves in Syrian hamsters. Anat Rec. 1996;244:490-8.

17. Wilson DI, Goodship JA, Burn J, Cross IE, Scambler PJ. Deletions within chromosome $22 \mathrm{q} 11$ in familial congenital heart disease. Lancet. 1992;340:573-5

18. Jiang X, Rowitch DH, Soriano P, McMahon AP, Sucov HM. Fate of the mammalian cardiac neural crest. Development. 2000;127: 1607-16.

19. Mitchell PJ, Timmons PM, Hebert JM, Rigby PW, Tjian R. Transcription factor AP-2 is expressed in neural crest cell lineages during mouse embryogenesis. Genes Dev. 1991;5:105-19.

20. Schorle H, Meier P, Buchert M, Jaenisch R, Mitchell PJ. Transcription factor AP-2 essential for cranial closure and craniofacial development. Nature. 1996;381:235-8.

21. Wang D, Shin TH, Kudlow JE. Transcription factor AP-2 controls transcription of the human transforming growth factor-alpha gene. J Biol Chem. 1997;272:14244-50.

22. McPherson LA, Baichwal VR, Weigel RJ. Identification of ERF-1 as a member of the AP2 transcription factor family. Proc Natl Acad Sci U S A. 1997;94:4342-7.

23. Frisch SM, Morisaki JH. Positive and negative transcriptional elements of the human type IV collagenase gene. Mol Cell Biol. 1990; 10:6524-32.

24. Duan C, Clemmons DR. Transcription factor AP-2 regulates human insulin-like growth factor binding protein-5 gene expression. $J$ Biol Chem. 1995;270:24844-51.

25. Hierck BP, Molin DG, Boot MJ, Poelmann RE, Gittenberger-De Groot AC. A chicken model for DGCR6 as a modifier gene in the DiGeorge critical region. Pediatr Res. 2004;56:440-8.

26. Ranger AM, Grusby MJ, Hodge MR, Gravallese EM, de la Brousse FC, Hoey T, et al. The transcription factor NF-Atc is essential for cardiac valve formation. Nature. 1998;12:186-90.

27. de la Pompa JL, Timmerman LA, Takimoto H, Yoshida H, Elia AJ, Samper E, et al. Role of the NF-Atc transcription factor in morphogenesis of cardiac valves and septum. Nature. 1998;12:182-6.

28. Schilham MW, Oosterwegel MA, Moerer P, Ya J, de Boer PA, van de Wetering $M$, et al. Defects in cardiac outflow tract formation and pro-B-lymphocyte expansion in mice lacking Sox-4. Nature. 1996; 380:711-4.

29. Yacoub MH, Cohn LH. Novel approaches to cardiac valve repair from structure to function: part I. Circulation. 2004;109:942-50.

\section{JTCVS On-Line Manuscript Submission and Review}

The Journal of Thoracic and Cardiovascular Surgery requires authors and reviewers to submit all new and revised manuscripts and reviews via Editorial Manager. Point your browser to http://jtcvs.editorialmanager.com, log in as author or reviewer (as appropriate), and follow the instructions provided.

To retrieve your username and password, click "Forget your password?" on the Editorial Manager log-in page.

If you have questions or experience problems uploading your manuscript or review, please contact the editorial office:

Telephone: 215-762-1854

E-mail: jtcvs@drexel.edu 